\title{
Pain and cognitive status among nursing home residents in Canada
}

\author{
Wendey R Proctor MSc ${ }^{1}$, John P Hirdes $\mathrm{PhD}^{1,2}$
}

WR Proctor, JP Hirdes.

Pain and cognitive status among nursing home residents in Canada.

Pain Res Manage 2001;6(3):119-125.

BACKGROUND: There is little information available on the rates of pain in institutionalized elderly persons, and this is particularly true for Canada.

OBJECTIVES: To provide information about the prevalence and clinical correlates of pain in a sample of Canadian nursing homes, to determine whether residents with cognitive impairment experience lower rates of health conditions associated with pain (eg, arthritis) than residents without cognitive impairment and to determine whether the associations (ie, odds ratios) for pain with such health conditions vary as a function of cognitive status.

DESIGN: The study is based on a secondary analysis of data collected with the minimum data set (MDS 2.0).

SETTING AND PARTICIPANTS: The study comprised 3195 nursing home residents in Ontario, Manitoba and Saskatchewan. SUBJECTS AND METHODS: All residents were assessed with the MDS 2.0 by trained clinicians (usually nurses). Pain was documented if it had occurred within the seven days before the assessment. Assessors were trained to look for overt signs of discomfort, such as wincing or verbalizations. Self-report ratings were obtained when possible.
RESULTS: The overall prevalence of pain in this sample was $49.7 \%$, and $23.7 \%$ of residents experienced pain daily. Persons with and persons without cognitive impairments did not differ with respect to the prevalence of conditions likely to cause pain and the associations of pain with such health conditions. Regional differences were found, with Ontario residents having a higher frequency and intensity of pain than their counterparts in Saskatchewan and Manitoba. This may be due, at least in part, to regional differences in nursing home admission criteria.

CONCLUSIONS: The findings suggest that the prevalence of identified pain is lower among nursing home residents with higher levels of cognitive impairment. These results do not support the notion that this is a function of lower prevalence rates of pain-causing conditions in nursing home residents with dementia. Furthermore, the results do not support the view that residents with cognitive impairments are less sensitive to pain. This study highlights the need for more comprehensive tools to assess pain in persons with cognitive impairments. Nonetheless, the MDS may be a useful instrument for detecting pain in such populations, because it does not rely exclusively on self-report.

Key Words: Aging; Dementia, Long-term care; Minimum data set; Pain

Pour le résumé, voir page suivante

${ }^{1}$ Department of Health Studies and Gerontology, University of Waterloo, Waterloo, Ontario; ${ }^{2}$ Canadian Collaborating Centre - inter RAl, Providence Centre, Toronto, Ontario

Correspondence and reprints: Dr John P Hirdes, Department of Health Studies and Gerontology, University of Waterloo, Waterloo, Ontario N2L 3G1. Telephone 519-888-4567 ext 2007, fax 519-746-2510, e-mail hirdes@healthy.uwaterloo.ca 


\section{Douleur et état cognitif chez les pensionnaires vivant dans des maisons de soins infirmiers au Canada}

CONTEXTE : Il existe très peu d'information, en particulier au Canada, sur la fréquence de la douleur chez les personnes âgées gardées en établissement.

OBJECTIFS : Recueillir de l'information sur la prévalence de la douleur et ses corrélats cliniques dans un échantillon de maisons de soins infirmiers établies au Canada pour savoir si les pensionnaires ayant des troubles cognitifs connaissent des taux plus faibles d'affections associées à la douleur, par exemple l'arthrite, que les pensionnaires exempts de troubles cognitifs et pour déterminer si les relations, c'est-à-dire le risque relatif approché, établies entre la douleur et ces affections varient en fonction de l'état cognitif.

PLAN D'ÉTUDE : L'étude repose sur une analyse secondaire de données recueillies à l'aide de l'ensemble minimal de données (MDS 2.0).

LIEU ET PARTICIPANTS : L'étude porte sur 3195 pensionnaires vivant dans des maisons de soins infirmiers établies en Ontario, au Manitoba et en Saskatchewan.

SUJETS ET MÉTHODE : Tous les sujets ont été évalués à l'aide du MDS 2.0 par du personnel clinicien, habituellement infirmier, formé à cette fin. La douleur a été notée si elle avait été ressentie au cours des sept jours précédant l'évaluation. Les éva- luateurs ont été formés à déceler des signes manifestes de malaise, comme les grimaces et la verbalisation. On a recueilli, dans la mesure du possible, des auto-évaluations

RÉSULTATS : La prévalence globale de la douleur dans l'échantillon était de 49,7\%, et 23,7\% des patients éprouvaient de la douleur tous les jours. Il n'y avait pas de différence entre les pensionnaires qui avaient des troubles cognitifs et ceux qui n'en avaient pas quant à la prévalence des affections susceptibles de causer de la douleur et les liens entre la douleur et ces affections. On a relevé toutefois des différences régionales; en effet, les pensionnaires en Ontario connaissaient une fréquence et une intensité plus fortes de la douleur que les pensionnaires vivant au Manitoba ou en Saskatchewan.

CONCLUSIONS : Les résultats donnent à penser que la prévalence de douleurs définies diminue parmi les pensionnaires de maisons de soins infirmiers qui connaissent des troubles importants de la cognition. Les résultats infirment le concept selon lequel la diminution est fonction d'un taux de prévalence plus faible d'affections douloureuses parmi les pensionnaires atteints de démence, pas plus qu'ils n'étayaient le point de vue selon lequel les personnes atteintes de troubles cognitifs sont moins sensibles à la douleur. Par ailleurs, l'étude a fait ressortir la nécessité de concevoir des outils plus généraux pour évaluer la douleur chez les personnes souffrant de troubles cognitifs. Néanmoins, le MDS peut s'avérer utile pour déceler la douleur dans ce type de population parce qu'il ne repose pas seulement sur l'auto-évaluation.
$\mathrm{P}$ ain among institutionalized elderly persons has received relatively little attention from researchers, despite the high likelihood that it affects the quality of life of a substantial proportion of this population. The absence of this information is particularly pronounced in Canada. Estimates of the prevalence of pain in nursing homes generally range from $49 \%$ to $86 \%$ (1-7). Many of the relevant studies have had small sample sizes. Furthermore, they have varied with respect to pain assessment tools and patient selection criteria. Cognitively impaired individuals were typically excluded from these studies because of the difficulties in assessing their pain. For instance, Ferrell et al (6) showed that $17 \%$ of nursing home residents with cognitive impairment who were able to communicate were not able to make their pain known on at least one of five self-report measures of pain. Further, it cannot be assumed that estimates of pain within a subset of cognitively intact residents are generalizable to those with cognitive impairment.

Efforts have been made to overcome at least some of these problems by using data collected through minimum data set (MDS) assessments. The MDS approach focuses on physical, cognitive and emotional functioning as well as on common medical conditions (8). Assessors using the MDS are trained to look for overt symptoms of pain or discomfort (eg, grimacing, tenderness). They are also trained to obtain subjective reports of pain from the patient. The frequency of pain is coded in terms of its occurrence in the past seven days. The intensity of the pain is coded as 'mild', 'moderate' or 'times when it is horrible or excruciating', based on the resident's subjective rating (or staff ratings of observ- able indicators in those not able to communicate). Won et al (9) studied 49,971 residents in the United States using the MDS and found that $26 \%$ had daily pain. These researchers excluded all residents with cancer or severe cognitive impairment, and those with a terminal prognosis. FinneSoveri et al (10) studied 6487 nursing home residents from four Nordic countries and found the prevalence of daily pain to be about $23 \%$ using the MDS. These estimates are much lower than those reported in other studies of pain in the nursing home, possibly reflecting the inclusion of a broader population of seniors (ie, nursing home residents with cognitive impairments were not excluded).

Arthritis and musculoskeletal conditions are among the most common clinical correlates of pain in nursing homes $(4,6,10)$, and muscles and joints are common sites of pain $(2,7,11)$. As well, these conditions are known to have a high prevalence within the nursing home, leading to an increase in the at-risk population for pain. Pain has also been found to be common among residents with depression $(9,12-15)$, but it is not clear whether elevations in pain report are a result of or a risk factor for depression. That is, factors other than disease may be important determinants of pain ratings.

Residents with cognitive impairments are typically excluded from pain studies because they are likely unable to respond to standardized, subjective pain measures. Hence, little is known about the relationship between cognition and pain in institutionalized elderly persons. Pain ratings have been reported to be inversely related to cognitive status. Sengstaken and King (4) found that pain was detected in only $17 \%$ of noncommunicative nursing home residents 
compared with $43 \%$ of communicative nursing home residents. Parmelee et al (3) determined that residents with cognitive impairment indicated that they experienced less pain than did cognitively intact residents. These researchers also showed that pain ratings were consistent across measures and were stable over four- and eight-week intervals. These results suggest that, although pain may be underdetected in this population, individual reports of pain appear to be stable over time, which supports their reliability.

The apparent negative correlation of pain with cognitive impairment may be attributable to a number of factors. First, it may be the result of a bias among clinicians, making them less sensitive to the signs of pain in persons with dementia. Second, it is possible that dementia modifies the individual's awareness of and/or response to pain. This issue has been examined by using facial expressions to evaluate pain in seniors with cognitive impairments and seniors without cognitive impairments $(16,17)$, and there was no evidence of reduced pain reactivity among seniors with dementia. Third, dementia may be associated with lower rates of other factors known to cause pain, resulting in spurious negative associations of dementia with pain. In that case, the absence of pain-inducing physical conditions rather than dementia would explain the lower levels of pain. One can examine the latter two arguments by comparing the prevalence rate of conditions known to cause pain in persons who are cognitively intact with corresponding prevalence rates in persons who have cognitive impairments. If dementia alters the resident's sensitivity or response to pain, one would expect that the association (estimated with odds ratios) of MDS pain ratings and such health conditions would be lower among persons with dementia. Data from MDS 2.0 assessments are also used to document the prevalence and clinical correlates of pain in elderly individuals in Canadian nursing homes. Moreover, we examined differences in these associations between persons with and persons without cognitive impairments. To the best of our knowledge, this is the first Canadian study of pain prevalence in nursing homes that involves a large sample $(n=3195)$ of participants.

\section{SUBJECTS AND METHODS}

\section{Study population}

MDS 2.0 is an instrument used for care planning, funding and assessment of quality within the nursing home, where data for the assessment are collected by the 14th day since admission (18). The MDS instrument has been subject to extensive international testing for reliability and validity (19-21). MDS 2.0 assessments were completed in nursing homes in Ontario, Manitoba and Saskatchewan by nurses and other clinicians who had attended a two-day training program on the instrument. Ontario sites included Providence Centre $(n=200)$ and Copernicus Lodge $(n=80)$ in Toronto, Ontario, and two long term care facilities associated with the Sisters of Charity of Ottawa Elisabeth Bruyere Hospital in Ottawa, Ontario $(n=100)$. Saskatchewan data included all residents of nursing homes in the Prince Albert
Health District $(n=2488)$. Finally, Manitoba data were derived from four nursing homes $(n=625)$ participating in a provincial pilot funded by Manitoba Health.

\section{Demographic and clinical information}

All demographic data were derived from personal items and referral items on MDS 2.0 assessments. An Activities of Daily Living (ADL) summary score was used as a measure of physical function. The ADL-short form is a scale that is based on data within the MDS 2.0 assessment and evaluates the degree of assistance needed by a nursing home resident in four areas: personal hygiene, toilet use, locomotion and eating (22). For each area, a resident receives a score from zero (independent) to six (totally dependent). Disease diagnoses were coded according to International Classification of Disease, 9th revision criteria, and were derived from the resident's medical file. As well, symptom information was gathered from the medical chart and observations of ward staff, as specified by the MDS 2.0 guidelines.

Pain was documented if it had occurred within the seven days before the assessment. Assessors were trained not only to ask about pain, but also to look for overt signs, such as wincing or verbalizations, indicating discomfort. Residents who indicated that they had pain or showed evidence of pain were coded as having either daily pain or less than daily pain. Further, residents with pain were asked to rate the intensity of that pain within the past seven days. If they were not able to provide a subjective rating, staff members estimated the pain severity based on their observations of the resident's behaviour.

\section{Cognitive performance}

The mental status of each resident was assessed using the Cognitive Performance Scale (CPS) (23). The CPS uses data from MDS 2.0 items to place individuals into one of seven cognition categories, ranging from cognitively intact (score of 0 ) to severe cognitive impairment (score of 6). Five items are included in the calculation of the CPS: short term memory, daily decision-making ability, comatose state, making self understood and ability to eat independently. The CPS has shown excellent agreement with the Mini-Mental State Examination (24) and has the benefit of classifying each individual in a standardized manner.

\section{Statistical analysis}

Only residents who were 65 years of age or older at the time of assessment were included in the study sample. Results were tabulated for the total sample and by the province in which the data were collected. $\chi^{2}$ was used to assess the statistical significance of associations between clinical and other health-related conditions in the total sample. Separate analyses were conducted when the sample was stratified into those with no or mild cognitive impairment, and those with severe cognitive impairment. Confidence intervals were constructed for all odds ratios to determine the precision of these estimates and the significance of differences between groups. 
TABLE 1

Sample characteristics of Canadian nursing home residents by province

\begin{tabular}{|c|c|c|c|c|}
\hline & Manitoba $(n=591)$ & Ontario $(n=363)$ & Saskatchewan $(n=2241)$ & Total sample $(n=3195)$ \\
\hline Mean age, years (range) & 85.5 (65 to 105$)$ & 84.8 (65 to 104$)$ & $84.6(65$ to 103$)$ & $84.8(65$ to 105$)$ \\
\hline \multicolumn{5}{|l|}{ Age groups, years (\%) } \\
\hline 65 to 74 & 9.0 & 13.5 & 12.1 & 11.7 \\
\hline 75 to 84 & 37.1 & 33.3 & 35.3 & 35.4 \\
\hline$\geq 85$ & 54.0 & 53.2 & 52.6 & 52.9 \\
\hline Sex (\% female) & 74.8 & 77.0 & 66.2 & 69.0 \\
\hline Mean length of stay \pm SD & $3.0 \pm 2.9$ & $4.0 \pm 4.3$ & $3.5 \pm 3.8$ & $3.4 \pm 3.7$ \\
\hline $\begin{array}{l}\text { Number of prescribed } \\
\text { medications (range) }\end{array}$ & 5.6 (0 to 23$)$ & $5.4(0$ to 24$)$ & $6.3(0$ to 24$)$ & $6.0(0$ to 24$)$ \\
\hline Mean CPS score \pm SD & $3.2 \pm 2.0$ & $3.0 \pm 2.2$ & $2.9 \pm 2.0$ & $3.0 \pm 2.0$ \\
\hline \multicolumn{5}{|l|}{ Cognition (\%) } \\
\hline Cognitively intact & 22.0 & 33.5 & 29.4 & 28.5 \\
\hline Severe cognitive impairment & 35.2 & 40.0 & 29.6 & 31.6 \\
\hline Mean ADL score $\pm \mathrm{SD}$ & $7.4 \pm 5.8$ & $7.6 \pm 5.8$ & $8.3 \pm 5.8$ & $8.1 \pm 5.8$ \\
\hline
\end{tabular}

ADL Activity of Daily Living; CPS Cognitive Performance Scale

TABLE 2

Prevalence of pain among Canadian nursing home residents $(n=3195)$

\begin{tabular}{lc}
\hline Pain characteristic & $\mathbf{n}(\%)$ \\
\hline Frequency & $1605(50.2)$ \\
$\quad$ None & $829(26.0)$ \\
Less than daily & $758(23.7)$ \\
Daily & \\
Intensity & $1605(50.2)$ \\
None & $793(24.8)$ \\
Mild & $718(22.5)$ \\
Moderate & $79(2.5)$ \\
Excruciating at times
\end{tabular}

The total number of cases may be less than 3195 because of item nonresponse

\section{RESULTS}

\section{Sample demographics}

When limited to those aged 65 years and over, the final sample comprised 3195 nursing home residents, with a mean age of 83.8 years (range 65 to 105 years). The majority of the residents were over the age of 85 years $(n=1691)$, and $70 \%$ were female (Table 1 ). The average length of stay in the nursing homes was $3.43 \pm 3.72$ years (mean $\pm \mathrm{SD}$ ). Residents were prescribed an average of 6.03 medications (range zero to 24). Scores on the ADL scale ranged from 0 to 16 , with a mean of $8.1 \pm 5.8$, and $20.5 \%$ of residents fell into the categories for the greatest physical impairments. CPS scores ranged from 0 to 6 , with a mean of $2.98 \pm 2.03$. Approximately $31.6 \%$ of residents showed signs of severe cognitive impairment, while $28.5 \%$ were considered to be relatively cognitively intact.
TABLE 3

Prevalence of pain among Canadian nursing home residents by province $(n=3195)$

\begin{tabular}{lcrc}
\hline $\begin{array}{l}\text { Pain } \\
\text { characteristic }\end{array}$ & $\begin{array}{c}\text { Manitoba } \\
\mathbf{n}(\%)\end{array}$ & $\begin{array}{c}\text { Ontario } \\
\mathbf{n}(\%)\end{array}$ & $\begin{array}{c}\text { Saskatchewan } \\
\mathbf{n}(\%)\end{array}$ \\
\hline $\begin{array}{l}\text { Frequency* } \\
\quad \text { None }\end{array}$ & $307(52.0)$ & $153(42.5)$ & $1145(51.1)$ \\
$\quad$ Less than daily & $157(26.6)$ & $90(25.0)$ & $582(26.0)$ \\
$\quad$ Daily & $127(21.5)$ & $117(32.5)$ & $514(22.9)$ \\
Intensity** & & & \\
$\quad \begin{array}{l}\text { Mild } \\
\quad \text { Moderate }\end{array}$ & $126(44.5)$ & $65(30.4)$ & $602(55.1)$ \\
$\quad \begin{array}{l}\text { Excrutiating at } \\
\text { times }\end{array}$ & $3(6.0)$ & $27(12.6)$ & $46(4.2)$ \\
\hline
\end{tabular}

The total number of cases may be less than 3195 because of item nonresponse. Pain intensity is rated only for those cases who reported at least less than daily pain. ${ }^{*} P<0.001 ;{ }^{*} P<0.0001$

\section{Prevalence of pain}

Of the 3195 nursing home residents included in the analysis, $1587(49.7 \%)$ had pain, whether it was daily or on at least one occasion within the seven-day assessment period (Table 2). Of the residents with pain, slightly more than half had pain less than daily, while the remainder indicated that they had daily pain. About $25 \%$ of residents rated their pain as mild, $22.5 \%$ as moderate, and $2.5 \%$ as 'times when pain is horrible or excruciating'.

Pain did not increase noticeably with age; about $50 \%$ of residents 65 to 74 years of age had pain compared with about $52 \%$ of those over the age of 85 years. Further, pain was more prevalent among women, $53.0 \%$ of whom had pain during the seven-day assessment period compared with $42.5 \%$ of males (OR 1.51; CI 1.32 to 1.79 ). Regional differences were examined by comparing pain frequency and 
TABLE 4

Prevalence of various clinical conditions and their associations with daily pain in Canadian nursing home residents

\begin{tabular}{|c|c|c|c|}
\hline Diagnosis & $\begin{array}{c}\text { Prevalence } \\
\text { n (\%) }\end{array}$ & Odds ratio & $95 \% \mathrm{Cl}$ \\
\hline \multicolumn{4}{|l|}{ Entire sample } \\
\hline Arthritis* & $513(16.1)$ & 2.61 & $2.13-3.20$ \\
\hline Cancer & $92(2.9)$ & 1.01 & $0.67-1.53$ \\
\hline Diabetes & $239(7.5)$ & 1.08 & $0.83-1.40$ \\
\hline $\begin{array}{l}\text { Congestive heart } \\
\text { failure* }^{*}\end{array}$ & $214(6.7)$ & 1.47 & $1.10-1.93$ \\
\hline Hip fracture* & $226(7.1)$ & 1.93 & $1.47-2.56$ \\
\hline Osteoporosis* & $117(3.7)$ & 2.55 & $1.70-3.82$ \\
\hline Pressure ulcer* & 251 (7.9) & 1.67 & $1.28-2.18$ \\
\hline $\begin{array}{l}\text { Urinary tract } \\
\text { infection* }\end{array}$ & $127(3.8)$ & 2.05 & $1.40-3.01$ \\
\hline Depression* & 394 (12.3) & 1.64 & $1.32-2.03$ \\
\hline $\begin{array}{l}\text { Falls } \\
\text { Past } 30 \text { days* }\end{array}$ & $366(11.5)$ & 1.53 & $1.23-1.91$ \\
\hline Past 31 to 180 days & $482(15.1)$ & 1.13 & $0.93-1.37$ \\
\hline Unsteady gait* & $656(20.6)$ & 1.40 & $1.18-1.67$ \\
\hline $\begin{array}{l}\text { Do not resuscitate } \\
\text { order }\end{array}$ & $861(27.0)$ & 1.15 & $0.98-1.34$ \\
\hline $\begin{array}{l}\text { Verbally abusive } \\
\text { behaviour }\end{array}$ & $518(16.3)$ & 0.83 & $0.69-1.00$ \\
\hline \multicolumn{4}{|l|}{ Cognitively intact residents } \\
\hline Arthritis* & 199 (21.8) & 2.40 & $1.68-3.44$ \\
\hline Cancer & $30(3.3)$ & 0.71 & $0.34-1.47$ \\
\hline Diabetes & $80(8.8)$ & 1.42 & $0.87-2.32$ \\
\hline $\begin{array}{l}\text { Congestive heart } \\
\text { failure }\end{array}$ & $78(8.6)$ & 1.55 & $0.93-2.57$ \\
\hline Hip fracture & $72(7.9)$ & 1.46 & $0.87-2.46$ \\
\hline Osteoporosis* & $38(4.2)$ & 3.48 & $1.44-8.40$ \\
\hline Pressure ulcer* & $68(7.5)$ & 3.50 & $1.81-6.76$ \\
\hline Urinary tract infection & $50(5.5)$ & 1.65 & $0.88-3.11$ \\
\hline Depression & 168 (18.4) & 1.23 & $0.87-1.75$ \\
\hline \multicolumn{4}{|l|}{ Falls } \\
\hline Past 30 days & $93(10.2)$ & 0.85 & $0.55-1.32$ \\
\hline Past 31 to 180 days & $10(12.1)$ & 0.75 & $0.50-1.12$ \\
\hline Unsteady gait & $156(17.1)$ & 1.45 & $1.00-2.10$ \\
\hline $\begin{array}{l}\text { Do not resuscitate } \\
\text { order* }\end{array}$ & $202(22.2)$ & 1.80 & $1.27-2.53$ \\
\hline $\begin{array}{l}\text { Verbally abusive } \\
\text { behaviour* }\end{array}$ & $73(8.0)$ & 0.55 & $0.34-0.89$ \\
\hline
\end{tabular}

intensity by province (Table 3 ). In both cases, significant differences were found, with Ontario having a higher proportion of nursing home residents with daily pain and with higher intensity levels of pain.

\section{Factors associated with pain}

In the pain literature, several factors that were examined in this sample have been suggested to be associated with pain.

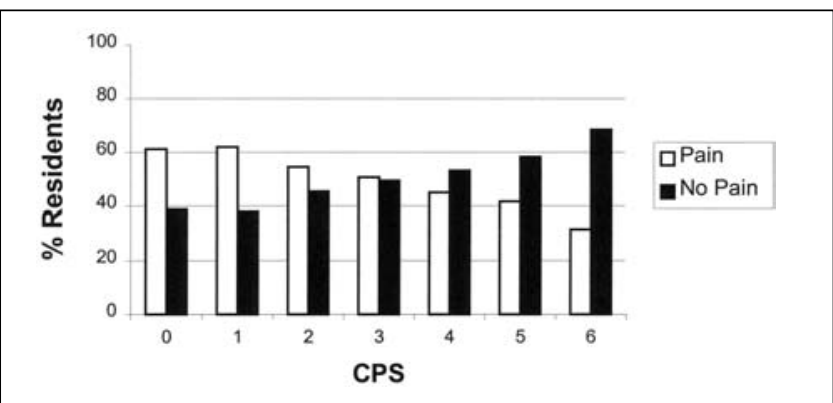

Figure 1) Percentage of Canadian nursing home residents with any pain by cognitive performance scale score (CPS) $(n=3193)$

TABLE 5

Prevalence of various clinical conditions and their associations with daily pain in Canadian nursing home residents with severe cognitive impairments $(n=1009)$

\begin{tabular}{lccc}
\hline Diagnosis & Prevalence, $\mathbf{n}$ (\%) & Odds ratio & $\mathbf{9 5 \%} \mathbf{~ C l}$ \\
\hline Arthritis* & $130(12.9)$ & 2.14 & $1.47-3.10$ \\
Cancer & $28(2.8)$ & 2.00 & $0.94-4.26$ \\
Diabetes & $60(6.0)$ & 0.66 & $0.37-1.17$ \\
Congestive heart failure & $48(4.8)$ & 0.93 & $0.51-1.71$ \\
Hip fracture* & $72(7.1)$ & 2.13 & $1.31-3.45$ \\
Osteoporosis* & $30(3.0)$ & 3.54 & $1.64-7.65$ \\
Pressure ulcer* & $119(11.8)$ & 1.80 & $1.23-2.65$ \\
Urinary tract infection & $27(2.7)$ & 1.60 & $0.74-3.45$ \\
Depression* & $79(7.8)$ & 2.72 & $1.70-4.34$ \\
Falls & & & \\
\multicolumn{1}{l}{ Past 30 days* } & $112(11.1)$ & 2.53 & $1.70-3.77$ \\
\multicolumn{1}{c}{ Past 31 to 180 days* } & $147(14.6)$ & 1.67 & $1.18-2.38$ \\
Unsteady gait* & $161(16.0)$ & 1.98 & $1.41-2.79$ \\
Do not resuscitate order & $340(33.7)$ & 1.00 & $0.77-1.32$ \\
Verbally abusive behaviour* & $236(23.7)$ & 1.67 & $1.24-2.25$ \\
\hline
\end{tabular}

${ }^{*} P<0.05$

Arthritis, congestive heart failure, hip fracture, osteoporosis, pressure ulcers, urinary tract infection, depression, a fall within the past 30 days and unsteady gait were all associated with significantly elevated odds ratios of pain (Table 4).

\section{Pain and cognitive status}

The prevalence of detected pain was clearly related to $\operatorname{cog}$ nitive status based on the CPS. The prevalence of detected pain decreased among the most severe cognitive impairment categories, and the prevalence of 'no pain' was higher in nursing home residents with cognitive impairments (Figure 1). About $61 \%$ of residents in the cognitively intact group were rated as having pain, whereas the same was true for only $31.5 \%$ of the group with the most severe cognitive impairments. Because cognitive function was related to pain indi- 
cators, separate analyses were done for factors associated with pain detection in both cognitively intact persons and persons with severe cognitive impairments.

Cognitively intact nursing home residents: When only cognitively intact nursing home residents were considered, fewer factors emerged as significantly associated with pain (Table 4). Residents with arthritis, osteoporosis, pressure ulcers and do not resuscitate orders were more likely to be in pain than residents without these conditions. Again, only one factor was associated with a decreased likelihood of pain. In this case, residents who engaged in verbally abusive behaviour were less likely to be rated as having pain $(\mathrm{OR}=0.55$; CI 0.34 to 0.89 ).

Residents with cognitive impairments: Similar to cognitively intact residents, residents with severe cognitive impairments were more likely to have pain in conjunction with arthritis, osteoporosis and pressure ulcers. Although the magnitude of some of these associations appears to be somewhat smaller in the impaired group, the confidence intervals for odds ratios in the two groups overlap (Table 5). In addition, having a hip fracture, clinical depression, unsteady gait and falls within 180 days yielded stronger associations with pain among residents with cognitive impairments than among residents who were cognitively intact. Also, in contrast to the association found in cognitively intact persons, nursing home residents with cognitive impairments who engaged in verbally abusive behaviour were more likely to have pain recorded (OR 1.67; CI 1.24 to 2.25).

\section{DISCUSSION}

The present study shows that, among Canadian nursing home residents, the prevalence of either daily or less than daily pain was $49.7 \%$ and that $23.7 \%$ of residents experienced daily pain. This is similar to estimates reported in other countries where researchers have used MDS-based data $(9,10)$. These estimates are lower than those generated in studies that did not involve the MDS (1-7), which probably reflects the inclusion of large samples of cognitively impaired residents through the use of the MDS. By allowing assessors to consider overt signs and to consult with other health care providers, rather than relying only on subjective reports, the MDS is a more thorough assessment of the resident's pain than are subjective assessments. This suggests the MDS should be more sensitive to the presence of pain in persons with cognitive impairment than self-report measures, although future research is needed to verify this notion. One limitation with this approach is that staff may overestimate pain if they simply impute its presence based on the existence of pain-causing conditions. This speaks to the need for careful training of clinicians to ensure appropriate use of the instrument. It is also more likely that the primary assessment challenge is the underdetection of pain.

Fewer complaints of pain among residents with cognitive impairments is not a new finding. Parmelee (25) found that, although rates of potentially painful conditions did not differ as a function of cognitive status, those with impairments were significantly less likely to report pain. Also, in a small study of residents with Alzheimer's disease, 26 had potentially painful diagnoses, but only three presented with behaviours suggestive of pain (26). The present results show that, among conditions causing pain, only arthritis had a considerably lower prevalence among persons with cognitive impairments than among those who were cognitively intact. However, it is unlikely that lower rates of arthritis alone are responsible for the cognitive status-based differences in detected pain.

There may be a few explanations for the higher pain frequency and higher pain intensity in Ontario nursing homes. First, pain management may be more effective in Manitoba and Saskatchewan, but this could not be tested in the present study due to the lack of data on analgesic use. Second, other underlying factors not addressed in this analysis may account for these differences in pain. For example, the Ontario data included residents from two francophone nursing homes, and cultural elements may have led to differences in the manifestation of pain. It would be worthwhile to conduct research with larger nursing home samples (controlling for differences in cultural background) to test this hypothesis. Third, differences in admission patterns may mean that persons experiencing pain of high frequency and intensity are more likely to be admitted to Ontario homes than in other provinces.

There were some differences in the associations between various health conditions and pain when the data were stratified by cognition. However, the confidence intervals for most conditions related to pain overlapped when the two groups were compared. A number of factors were associated with pain in persons with cognitive impairments, but not in cognitively intact persons (ie, those with hip fracture, depression or unsteady gait). Perhaps nursing staff are more likely to document pain in residents with cognitive impairments when there are more obvious causes, such as falls. Given that numerous conditions have odds ratios for pain that are as strong or stronger than those for the cognitively intact population, these data do not support the argument that cognitive impairment reduces the sensitivity or responsiveness to pain.

Conditions such as arthritis, osteoporosis and pressure ulcers are common risk factors for pain, irrespective of cognitive status. Another interesting finding of this study, however, is the difference in the association of verbally abusive behaviour and pain between those with and those without cognitive impairments. When cognitively intact persons are considered, those who are verbally abusive are less likely to have pain. Among those with cognitive impairments, however, people who show such behaviours are more likely to be rated as having pain. Cognitively intact persons who act out may be perceived as threatening to nursing home staff, who in turn may spend too little time with the resident to pick up on pain behaviours. Residents with cognitive impairments who act out, however, may be assessed as having pain if these behaviours are believed to be linked to pain. Indeed, the MDS explicitly directs staff to consider 
this possibility as a means of increasing awareness of pain residents with dementia.

Although the task of assessing residents with cognitive impairments is difficult, it is important to make adequate pain management available to the resident. Previous research has already shown that noncommunicative nursing home residents are less likely to receive analgesia (4), which may be related to the nursing staff's difficulties in documenting their pain in the first place. As well, Won et al (9) found that both residents with borderline cognitive impairment and those with mild impairment were also less likely to receive analgesia for their pain. Horgas and Tsai (27) found that nursing home residents with cognitive impairments were prescribed and administered significantly less pain medication and smaller doses than those without impairment. Medication data were not available for this study, so it was not possible to determine whether undertreatment of pain occurred in this sample.

This study has confirmed previous prevalence estimates of daily pain in institutionalized elderly persons and documents a clear relationship between identifiable pain and

\section{REFERENCES}

1. Lau-Ting C, Phoon WO. Aches and pains among Singapore elderly. Singapore Med J 1988;29:164-7.

2. Ferrell BA, Ferrell BR, Osterweil D. Pain in the nursing home. J Am Geriatr Soc 1990;38:409-14.

3. Parmelee PA, Smith B, Katz IR. Pain complaints and cognitive status among elderly institution residents. J Am Geriatr Soc 1993;41:517-22.

4. Sengstaken EA, King SA. The problems of pain and its detection among geriatric nursing home residents. J Am Geriatr Soc 1993;41:541-4.

5. Mobily PR, Herr KA, Clark MK, Wallace RB. An epidemiologic analysis of pain in the elderly: the Iowa $65+$ rural health study. J Aging Health 1994;6:139-54.

6. Ferrell BA, Ferrell BR, Rivera L. Pain in cognitively impaired nursing home patients. J Pain Symptom Manage 1995;10:591-8.

7. Wagner AM, Goodwin M, Campbell B, et al. Pain prevalence and pain treatments for residents in Oregon nursing homes. Geriatr Nurs 1997; 18:268-72.

8. Hawes C, Morris JN, Phillips CD, Fries BE, Murphy K, Mor V. Development of the nursing home Resident Assessment Instrument in the USA. Age Ageing 1997;26:19-25.

9. Won A, Lapane K, Gambassi G, Bernabei R, Mor V, Lipsitz LA. Correlates and management of nonmalignant pain in the nursing home. SAGE Study Group. Systematic Assessment of Geriatric drug use via Epidemiology. J Am Geriatr Soc 1999;47:936-42.

10. Finne-Soveri H, Ljunggren G, Schroll M, et al. Pain and its association with disability in institutional long-term care in four Nordic countries. Can J Aging 2000;19:38-49.

11. Roy R, Thomas M. A survey of chronic pain in an elderly population. Can Fam Physician 1986;32:513-6.

12. Parmelee PA, Katz IR, Lawton MP. The relation of pain to depression among institutionalized aged. J Gerontol 1991;46:15-21.

13. Herr KA, Mobily PR. Geriatric mental health: chronic pain and depression. J Psychosoc Nurs 1992;30:7-12.

14. Williamson GM, Schulz R. Pain, activity restriction, and symptoms of cognitive status. The present findings suggest that cognitive status-based differences in pain ratings are not the result of differences in the rates of conditions causing pain or differences in the response or sensitivity to those conditions. Future research must continue to focus on refining tools for better assessing pain in cognitively impaired persons to ensure that they receive appropriate treatment. It is essential that both the clinical tools and staffing resources to assess and treat pain properly in nursing home residents are provided.

ACKNOWLEDGEMENTS: Data from Saskatchewan and Manitoba were made available through the Prince Albert Health District and Manitoba Health, respectively. The Providence Centre Foundation, Health Transition Fund - Health Canada, and the Canadian Institutes for Health Research provided financial support for this research. InterRAI is a 21-country research network that focuses on the development, application, and refinement of the RAI/MDS series of assessment instruments. The opinions expressed here are those of the authors and not necessarily those of the funding agencies.

depression among community-residing elderly adults. J Gerontol 1992;47:367-72.

15. Cohen-Mansfield J, Marx MS. Pain and depression in the nursing home: corroborating results. J Gerontol 1993;48:96-7.

16. Hadjistavropoulos T, LaChappelle DL, MacLeod FK, Hale C, O'Rourke N, Craig KD. Cognitive functioning and pain reaction in hospitalized elders. Pain Res Manage 1998;3:145-51.

17. Hadjistavropoulos T, LaChapelle DL, MacLeod FK, Snider B, Craig KD. Measuring movement-exacerbated pain in cognitively impaired frail elders. Clin J Pain 2000;16:54-63.

18. Hirdes JP, Fries BE, Morris JN, et al. Integrated health information systems based on the RAI/MDS series of instruments. Health Manage Forum 1999;12:30-40.

19. Morris J, Nonemaker S, Murphy K, et al. A commitment to change: revision of HCFA's RAI. J Am Geriatr Soc 1997;45:1011-6.

20. Sgadari A, Morris J, Fries BE, et al. Efforts to establish the reliability of the Resident Assessment Instrument. Age Ageing 1997;26:27-30.

21. Frederiksen K, Tariot P, Debner LK. Minimum Data Set Plus (MDS+) scores compared with scores from five rating scales. J Am Geriatr Soc 1996;44:305-9.

22. Morris J, Fries BE, Morris SA. Scaling ADLs within the MDS. J Gerontol A Biol Sci Med Sci 1999;54A:M546-53.

23. Morris J, Fries BE, Mehr DR, et al. MDS cognitive performance scale. J Gerontol A Biol Sci Med Sci 1994;49:M174-82.

24. Hartmaier SL, Sloane PD, Guess HA, Kock GG, Mitchell CM, Phillips CD. Validation of the Minimum Data Set cognitive performance scale: agreement with the Mini-Mental State examination. J Gerontol A Biol Sci Med Sci 1995;50A:M128-33.

25. Parmelee PA. Pain in cognitively impaired older persons. Clin Geriatr Med 1996;12:473-87.

26. Marzinski LR. The tragedy of dementia: clinically assessing pain in the confused nonverbal elderly. J Gerontol Nurs 1991;17:25-8.

27. Horgas AL, Tsai PF. Analgesic drug prescription and use in cognitively impaired nursing home residents. Nurs Res 1998;47:235-42. 


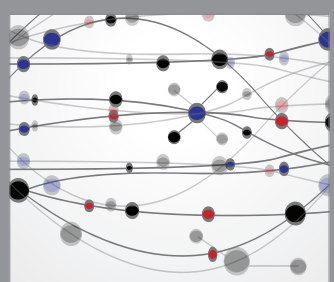

The Scientific World Journal
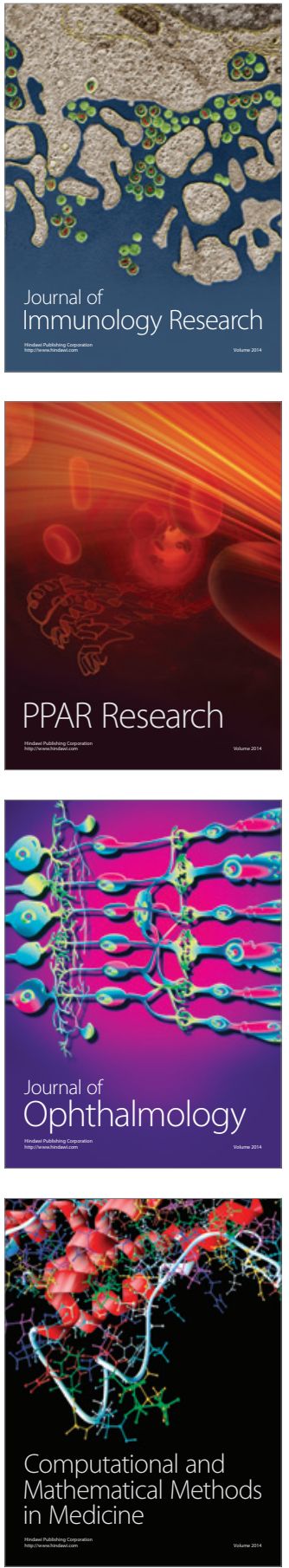

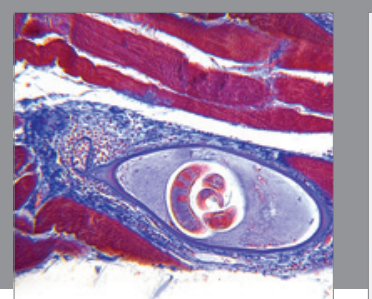

Gastroenterology Research and Practice

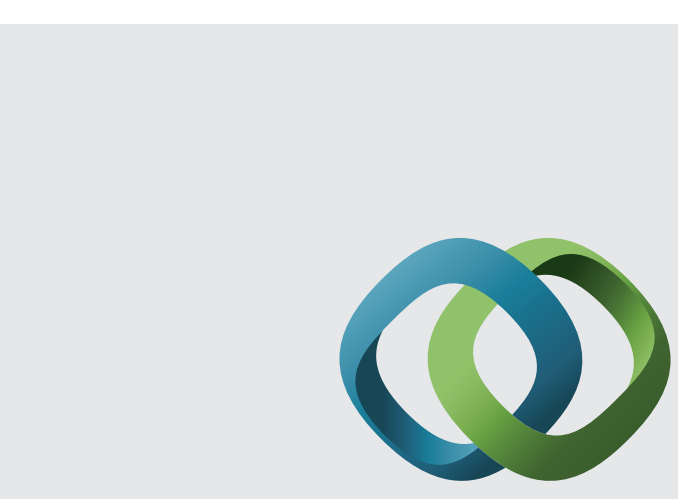

\section{Hindawi}

Submit your manuscripts at

http://www.hindawi.com
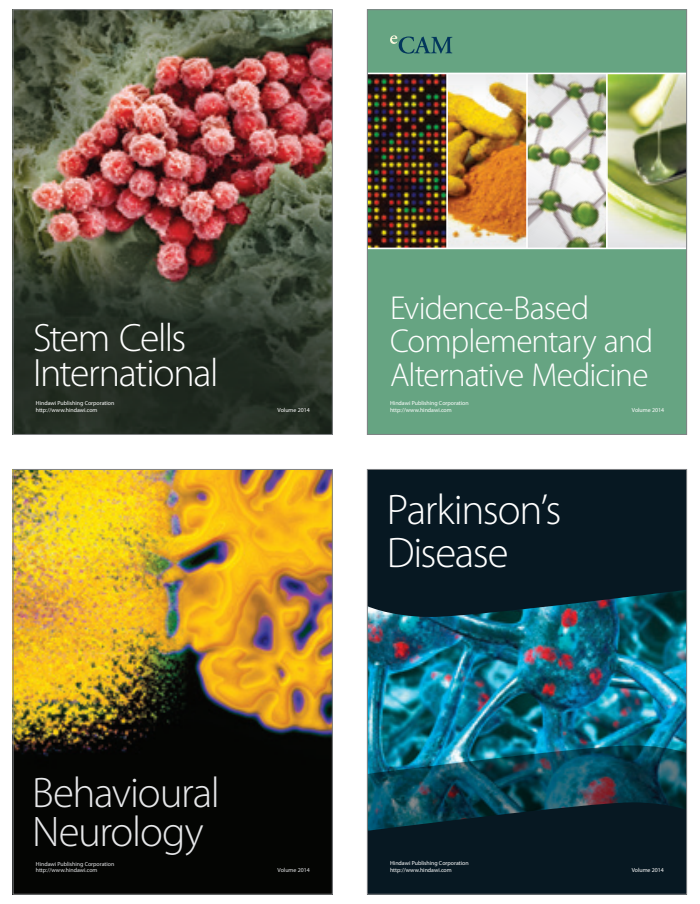
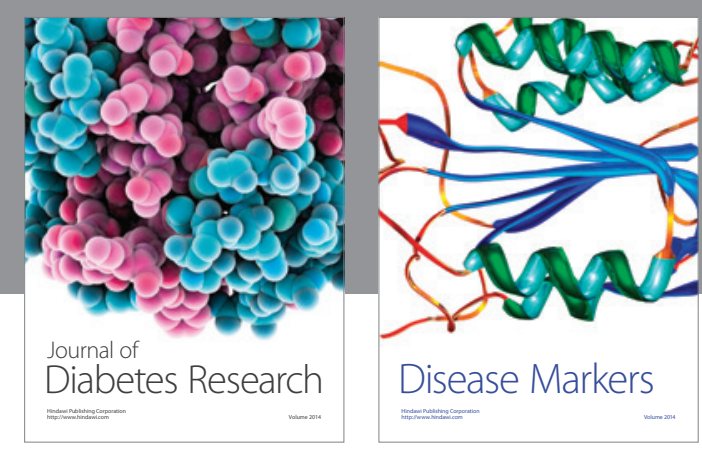

Disease Markers
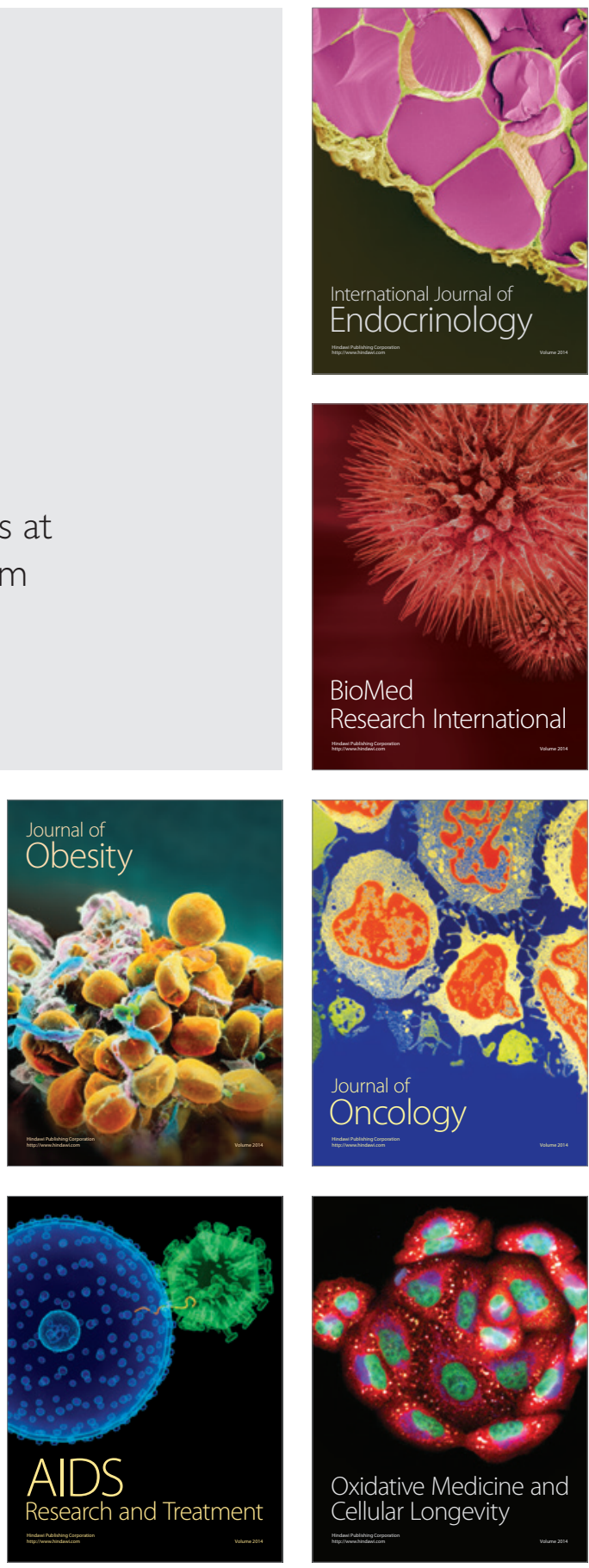